\title{
DIETA DE DUAS ESPÉCIES DE MORCEGOS FRUGÍVOROS (CHIROPTERA, PHYLLOSTOMIDAE) EM REMANESCENTES FLORESTAIS ALTERADOS NA ÁREA URBANA DE PONTA GROSSA, PR
}

\author{
FEEDING HABITS OF TWO SPECIES OF FRUGIVOROUS BATS \\ (CHIROPTERA, PHYLLOSTOMIDAE) FROM URBAN DISTURBED \\ FOREST PATCHES IN PONTA GROSSA, PR, SOUTHERN BRAZIL
}

\author{
Cristina Guilherme de Almeida ${ }^{1}$, Rosemeri Segecin Moro ${ }^{1 *}$, Cibele Maria \\ Vianna Zanon ${ }^{2}$ \\ 1* Autor para contato: Universidade Estadual de Ponta Grossa - UEPG, Departamento de \\ Biologia Geral, Campus em Uvaranas, Ponta Grossa, PR, Brasil; (42) 3220-3134; \\ e-mail: luzmoro@uepg.br \\ 2 Universidade Estadual de Londrina - UEL, Departamento de Biologia Animal e Vegetal, \\ Londrina, PR
}

Recebido para publicação em 11/11/2005

Aceito para publicação em 13/02/2006

\begin{abstract}
RESUMO
Como parte de um projeto de levantamento da fauna de quirópteros na área urbana do município de Ponta Grossa, PR, estabeleceu-se o hábito alimentar de duas espécies frugívoras locais. Foram visitados três pequenos remanescentes bastante antropizados da Floresta Ombrófila Mista, entre maio e outubro de 2002. Coletou-se material sob poleiros e também na defecação no instante da captura. A análise qualitativa do conteúdo fecal envolveu a secagem e catação manual de fragmentos, identificados sob lupa. Foram determinadas sementes pertencentes a nove táxons de Solanaceae, núculas de um táxon de Moraceae, sementes de um táxon de Piperaceae e sementes de um táxon de Rhamnaceae. Sturnira lilium (E. Geoffroy, 1810), presente nas três áreas, consome frutos de Ficus enormis (Mart. ex Miq.) Miq., Solanum americanum Hill., Solanum ciliatum Lam., Solanum erianthum Don., Solanum granuloso-leprosum Dunal, Vassobia breviflora (Sendth.) Hunz. e Piper gaudichaudianum Kunth. Artibeus lituratus (Olfers, 1818), também presente nas três áreas, alimenta-se de frutos de Solanum megalochitum Mark, Solanum erianthum Don., Solanum gemellum Mart. ex Sendt., Solanum sisymbrifolium Lam., Solanum sp., Ficus enormis (Mart. ex Miq.) Miq., Piper gaudichaudianum Kunt. e Hovenia dulcis Thumb. A literatura menciona ainda o gênero Cecropia como um item importante na dieta de quirópteros, mas esta não ocorre nas áreas em estudo. A análise dos elementos da dieta de Sturnira lilium e Artibeus lituratus indica que são espécies típicas de áreas perturbadas também na Floresta Ombrófila Mista. A alimentação ocorre
\end{abstract}


preferencialmente em espécies arbustivas com frutos expostos do tipo baga, com polpa, ao longo de ramos medianamente eretos, inacessíveis a animais que não voam.

Palavras-chave: Chiroptera, frugívoros, dieta, floresta ombrófila mista

\begin{abstract}
This study was carried out in the region of Ponta Grossa, in southern Brazil, in three areas of temperated forest fragments from May to October 2002. The feeding habits of two frugivorous bat species were studied through faeccal analysis of captured individuals. The study revealed that Artibeus lituratus shows preference for fruits of Moraceae (Ficus enormis), Solanaceae (Solanum americanum, Solanum ciliatum, Solanum erianthum, Solanum granulosoleprosum, Vassobia breviflora) and Piperaceae (Piper gaudichaudianum). Sturnira lilium prefers Solanaceae (Solanum megalochitum, Solanum erianthum, Solanum gemellum, Solanum sisymbrifolium, Solanum sp.), Moraceae (Ficus enormis), Piperaceae (Piper gaudichaudianum) and Rhamnaceae (Hovenia dulcis). Although Cecropia could be an important feeding component in other studies, it does not occur in this kind of forest. The analyzed seeds pointed out for disturbed areas as a major feeding source for these species, which prefer fruit exposed on erect branches on bushes that can not be reached by animals that do not fly.
\end{abstract}

Key words: Chiroptera, frugivorous, feeding habits, subtropical forest

\section{Introdução}

As plantas quiropterocóricas apresentam uma série de características que as diferenciam das plantas com frutos apreciados por aves e mamíferos nãovoadores, sendo este conjunto de atributos conhecido como "Síndrome da Quiropterocoria" (Muller; Reis, 1992): frutos de cor escura; de tamanho grande, com sementes também grandes; permanentemente presos às plantas e expostos fora da folhagem, e cheiro semelhante ao de substância azeda ou em fermentação. Três categorias de plantas quiroptecórias podem ser assim caracterizadas: plantas com frutos drupáceos e caroço duro; plantas com frutos de pericarpo doce e mole e de sementes relativamente grandes e escorregadias que se desprendem com facilidade da polpa; e plantas com frutos também de pericarpo doce e mole, mas com sementes relativamente pequenas, que mantêm o potencial germinativo mesmo depois de passar pelo tubo digestivo do animal (Pijl, 1972). Além disso, as flores se abrem à noite, quando os morcegos estão em atividade (Yalden; Morris, 1975).

A dispersão de sementes feita por morcegos frugívoros favorece o estabelecimento de espécies de plantas pioneiras, contribuindo para a regeneração de áreas através da sucessão secundária de espécies vegetais (Pijl, 1972). A relação dos quirópteros com as florestas subtropicais é bastante complexa. Em regiões de ocorrência da Floresta Ombrófila Mista, as alterações na vegetação e o impacto da antropização acelerada aumentam a necessidade de maiores estudos sobre este ecossistema (Bianconi; Miretzki, 2002). Este estudo integra um projeto pioneiro de levantamento da fauna de quirópteros da área urbana de Ponta Grossa, Paraná (Zanon, 2004), e pretendeu coletar informações sobre os itens alimentares consumidos por morcegos frugívoros ocorrentes nestas áreas. 


\section{Material e métodos}

As coletas foram realizadas em três pequenos fragmentos florestais localizados na área urbana do município de Ponta Grossa (2509’'S; 5007’W): Olaria Zuk, com 3,5 ha; Jardim Alphaville, com 2,0 ha; e Granja Santana, com 3,8 ha (Fig. 1). Originalmente, estas áreas eram cobertas por vegetação da Floresta Ombrófila Mista, caracterizada por Araucaria angustifolia e sub-bosque de Lauráceas e Mirtáceas (Takeda et al., 1998).

Atualmente as áreas pesquisadas apresentam uma cobertura vegetal contínua bastante perturbada, com exemplares de flora típicas da associação secundária da Floresta Ombrófila Mista (Takeda et al., 1998), destacando-se Prunus selowii (pessegueirobravo, Rosaceae), Schinus therebinthifolius (aroei- ra, Anacardiaceae), Piptocarpha angustifolia (vassourão-branco, Asteraceae), Vernonia discolor (vassourão-preto, Asteraceae), Mimosa scabrella (bracatinga, Mimosaceae), Jacaranda puberula (caroba, Bignoniaceae), Casearia sylvestris (guaçatonga, Flacourtiaceae), Cabralea canjerana (canjerana, Meliaceae), Cedrella fissilis (cedro-rosa, Meliaceae), Cinnamomum sellowianum (canela-garuva, Lauraceae), Ocotea puberula (canela-guaicá, Lauraceae), Crotonfloribundus (capixingui, Euphorbiaceae), Zanthoxyllum kleinii (juvevê, Rutaceae), Roupala brasiliensis (carvalho-nacional, Proteaceae) e Myrsine umbellata (capororoca, Myrsinaceae). Ocorrem também elementos isolados da floresta primária, como Ficus spp. (figueira, Moraceae), Erythrina falcata (corticeira, Fabaceae) e Anadenanthera colubrina (angico-branco, Mimosaceae).

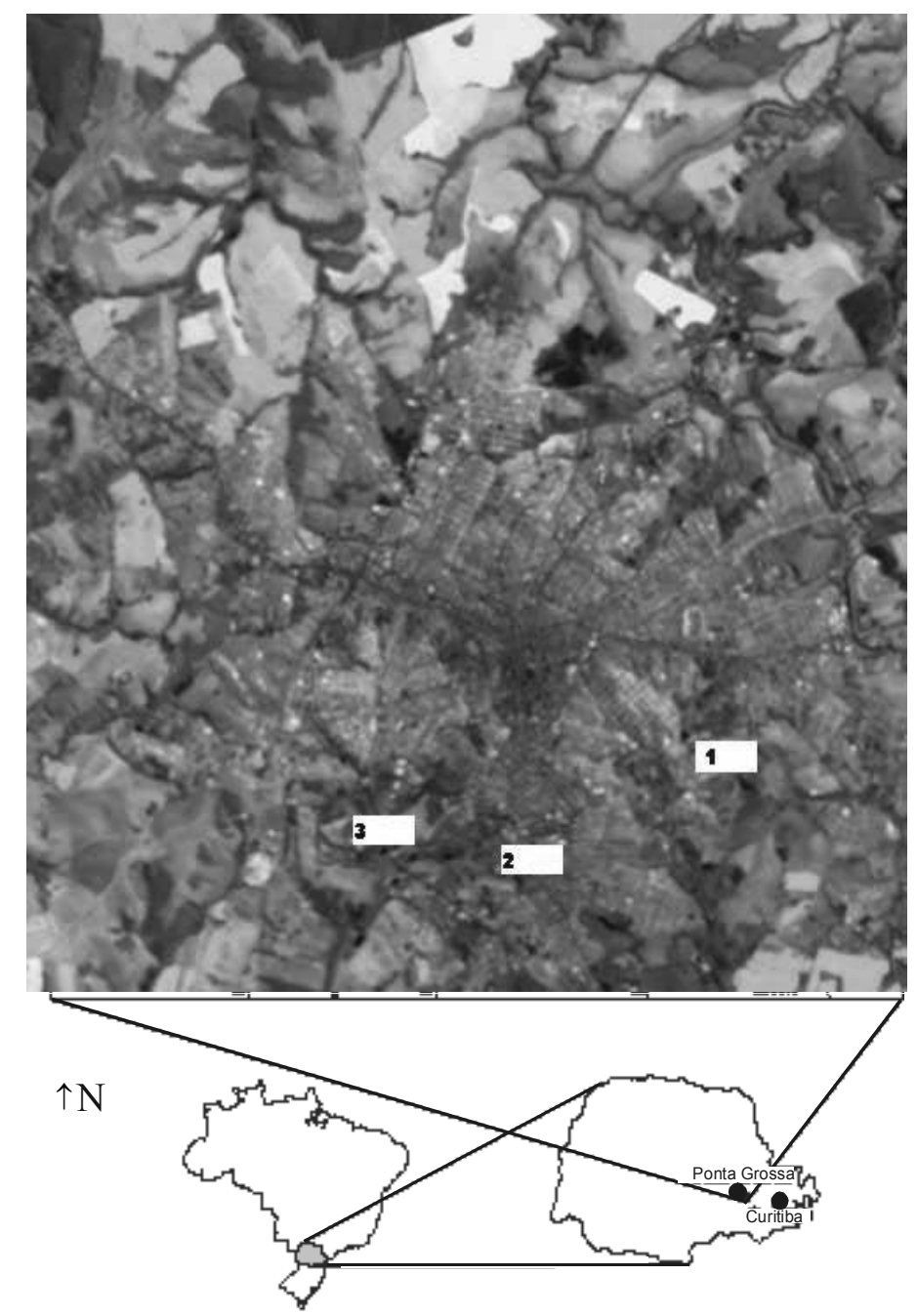

Figura 1 - Localização da área de estudo, com as estações de coleta: Olaria Zuk (1), Jardim Alphaville (2) e Granja Santana (3), na área urbana de Ponta Grossa, PR. 
O clima da região é do tipo $\mathrm{Cfb}$ de Koeppen, caracterizado por temperaturas médias de 15 a $17^{\circ} \mathrm{C}$, com mínimas de $2{ }^{\circ} \mathrm{C}$ e máximas de $22^{\circ} \mathrm{C}$, ocorrendo ao menos cinco geadas por ano e ocasionalmente neve. A umidade relativa do ar situa-se em torno dos $75 \% \mathrm{e}$ pluviosidade anual média de $1.480 \mathrm{~mm}$ (Melo et al., 2003).

A coleta de material fecal, no momento da captura, ocorreu entre setembro de 2002 e setembro de 2003; também foram observados poleiros, no intuito de averiguar a presença, neles, de sementes grandes não-ingeridas, pois elas poderiam indicar outros itens alimentares e também o transporte de frutos pelos frugívoros. Outra forma empregada para determinar a dieta foi, para os exemplares capturados com redes, mantê-los em pequenos sacos de pano por tempo suficiente para que defecassem, recolhendo-se então as fezes (Zanon, 2004). Para as espécies capturadas em abrigos, foram recolhidas fezes no próprio local de repouso.

O exame do conteúdo fecal envolveu a secagem e a seleção manual das sementes, que foram identificadas com o auxílio de microscópio estereoscópico. Foram feitas comparações das amostras vegetais obtidas com o acervo do Herbário da Universidade Estadual de Ponta Grossa (HUPG) e consultas à bibliografia para a região. Realizaram-se mensurações e ilustrações em fotomicroscópio estereoscópico (LEICA MZ6 e Câmara KODO Digital KC 512 NT) com captura de imagem pelo software EDIT STUDIO.

\section{Resultados}

Foram identificadas sementes de nove táxons de Solanaceae, um táxon de Piperaceae, um táxon de Rhamnaceae e núculas de um táxon de Moraceae. A espécie Sturnira lilium (E. Geoffroy, 1810), presente nas três áreas, consumiu frutos de Ficus enormis (Mart. ex Miq.) Miq. (Figura 2), Solanum americanum Hill. (Fig. 3), Solanum ciliatum Lam. (Figura 4), Solanum erianthum Don. (Figura 5), Solanum granulosoleprosum Dunal (Figura 6), Vassobia breviflora (Sendth.) Hunz. (Figura 7) e Piper gaudichaudianum Kunth (Figura 8). A espécie Artibeus lituratus (Olfers, 1818), também presente nas três áreas, alimentou-se de frutos de Solanum megalochitum Mark.(Figuras 9, 10), Solanum erianthum Don., Solanum gemellum Mart. ex Sendt. (Figura 11), Solanum sisymbrifolium Lam. (Figura 12), Solanum sp. (Figura 13), Ficus enormis (Mart. ex Miq.) Miq., Piper gaudichaudianum Kunth e Hovenia dulcis Thumb. (Figura 14). Embora a literatura mencione o gênero Cecropia como item importante na dieta de quirópteros, nas áreas em estudo este não ocorre. Frutos com sementes grandes, como Eriobotrya japonica L. (ameixa-amarela, Rosaceae) e Syagrus romanzoffianum (Cham.) Glass. (jerivá, Arecaceae), foram observados nos locais de captura. 


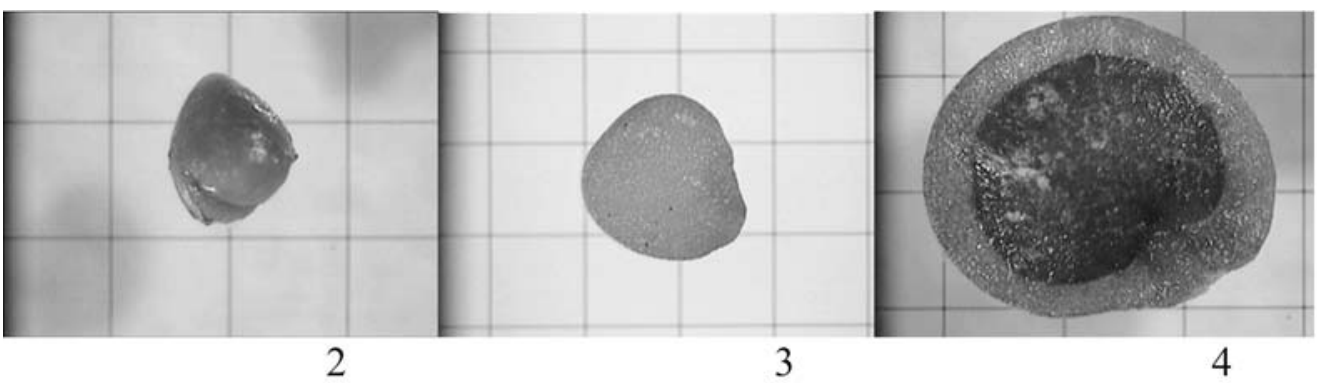

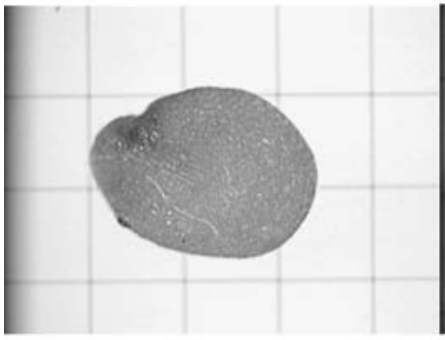

5

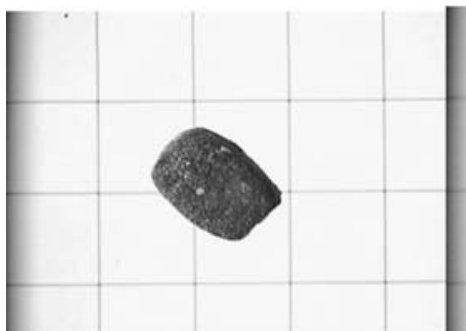

8

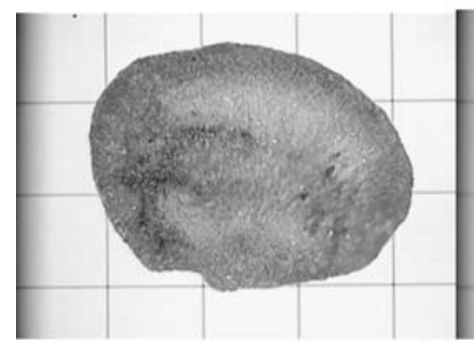

11

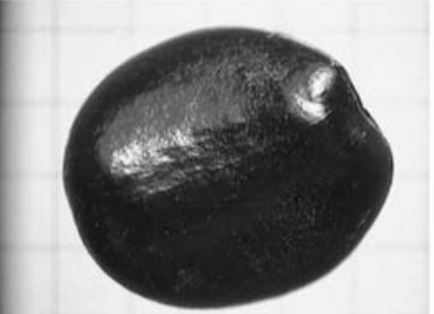

14

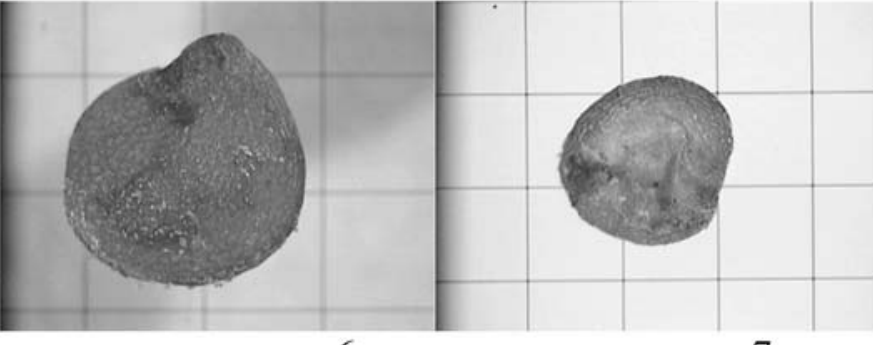

7

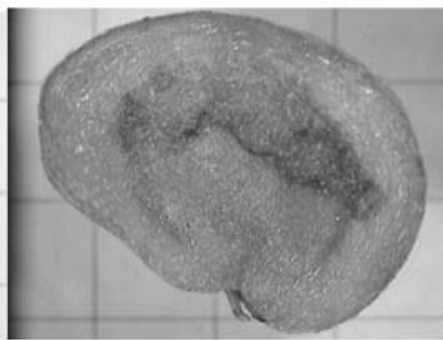

10

9

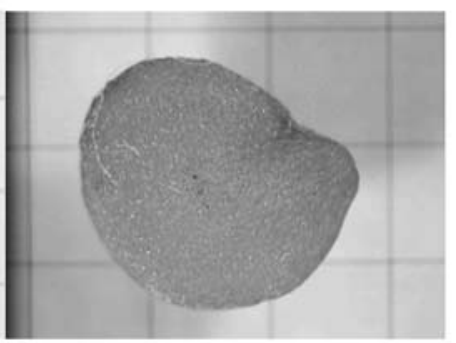

13

Figuras 2-14 - 2. Ficus enormis (Mart. ex Miq.) Miq. 3. Solanum americanum Hill. 4. Solanum ciliatum Lam. 5. Solanum erianthum Don. 6. Solanum granuloso-leprosum Dunal. 7. Vassobia breviflora (Sendth.) Hunz. 8. Piper gaudichaudianum Kunth. 9-10. Solanum megalochitum Mark. 11. Solanum gemellum Mart. ex Sendt. 12. Solanum sisymbrifolium Lam. 13. Solanum sp. 14. Hovenia dulcis Thumb. (cada quadrícula do retículo de fundo corresponde a $1 \mathrm{~mm}$ de lado) 


\section{Discussão}

Plantas das famílias Solanaceae e Piperaceae são bastante abundantes em áreas mais abertas, como bordas de mata e clareiras, caracterizando assim ambientes alterados. Frutos bacóides em Solanaceae presentes na área urbana de Ponta Grossa são encontrados nos gêneros Cestrum, Physalis e Solanum (Takeda et al., 1998; Moro et al., 2001). São frutos em geral globosos ou elipsóides, raramente alongados, com epicarpo fino, mais ou menos coriáceo ou carnoso, geralmente vermelho, amarelo ou alaranjado. Em Solanum e Physalis, a polpa origina-se por multiplicação do tecido placentar, produzindo um fruto solanídio onde placentas volumosas e carnosas delimitam pequenos lóculos cheios de substância sucosa (Barroso et al., 1999). Como em Cestrum esse caráter não se desenvolve, é possível que este não seja um item da dieta de quirópteros. As sementes de Solanum e Physalis são numerosas e muito pequenas, comprimidas ou reniformes, com bordos marginados ou alados. Os frutos indeiscentes de Piperaceae são diminutos, carnosos, com sementes apresentando perisperma e endosperma escassos e embrião reduzido. $\mathrm{O}$ atrativo para a fauna constitui-se pelo amentilho carnoso que suporta os frutos.

Os frutos compostos em Moraceae são constituídos por infrutescências policárpicas em Ficus, na forma de um sicônio piriforme, globoso ou elipsóide, carnoso, com pequena abertura apical e que encerra numerosas e pequenas núculas com estilete persistente, lateral, com semente pêndula (Barroso et al., 1999). Nas áreas em estudo, ocorrem as espécies Ficus enormis e Ficus landerstiana (Takeda et al., 1998).

Os frutos da espécie exótica Hovenia dulcis são globosos, do tipo cápsula, deiscente, possuindo sementes pequenas e achatadas, de cor marrom amareladas, localizando-se nas extremidades de pedúnculos intumescidos carnosos e sucosos que constituem um pseudofruto atraente para a fauna.

Reis et al. (2003), consideram as espécies Sturnira lilium e Artibeus lituratus habitantes de áreas perturbadas na Floresta Estacional. Dadas as condições atuais das áreas em estudo, verifica-se que estas espécies habitam áreas secundárias da Floresta Ombrófila Mista também. Quanto à sua ocorrência em áreas naturais bem conservadas nos Campos Gerais, Sturnira lilium foi observado no Parque Estadual de Vila Velha (Borges, 1989; IAP, 2004) e no Parque Estadual de Caxambu (Margarido, 1989), e registros históricos apontam que Artibeus lituratus já foi coletado nas proximidades de Vila Velha (Thomas, 1899). Ambas espécies foram também observadas nos parques estaduais de Guartelá (IAP, 2002a) e do Cerrado (IAP, 2002b)

\section{Conclusões}

A análise dos elementos da dieta de Sturnira lilium e Artibeus lituratus infere que estes quirópteros sejam espécies oportunistas e/ou generalistas, com capacidade de sobrevivência tanto em áreas naturais quanto perturbadas. A alimentação ocorre preferencialmente em espécies arbustivas com frutos expostos do tipo baga, com polpa, ao longo de ramos medianamente eretos, geralmente inatingíveis por animais incapazes de voar.

Agradecimentos

Ao CNPq e CAPES, pelo auxílio financeiro; ao biólogo Geovan Henrique Correa pelo auxílio com as imagens; ao professor Fernando Passos do Departamento de Zoologia da UFPR e a Simone Ferreira, técnica do Herbário UPCB da UFPR, pelo auxílio na determinação das espécies.

\section{REFERÊNCIAS}

1. BARROSO, G.M.; MORIM, M.P.; PEIXOTO, A.L.; ICHARO, C.L.F. Frutos e sementes: morfologia aplicada à Sistemática de Dicotiledôneas. Viçosa (MG): Editora da Universidade Federal de Viçosa, 1999.

2. BIANCONI, G.; MIRETZKI, M. Morcegos de um fragmento de floresta com Araucária do Estado do Paraná. In: CONGRESSO BRASILEIRO DE MASTOZOOLOGIA, 1, Porto Alegre, 2002. Resumos ...

3. BORGES, C.R.S. Composição mastofaunística do Parque Estadual de Vila Velha, Ponta Grossa, Paraná, Brasil. Curitiba, 1989. Dissertação (Mestrado em Zoologia). Universidade Federal do Paraná. 358p.

4. IAP - INSTITUTO AMBIENTAL DO PARANÁ. Plano de Manejo para o Parque Estadual do Guartelá - Avaliação 
Ecológica Rápida - Curitiba: Governo do Estado do Paraná/ STCP Engenharia de Projetos Ltda, 2002 (a).

5. _. Plano de Manejo para o Parque Estadual do Cerrado - Avaliação Ecológica Rápida - Curitiba: Governo do Estado do Paraná/ STCP Engenharia de Projetos Ltda, 2002 (b).

6. _. Plano de Manejo para o Parque Estadual de Vila Velha - Avaliação Ecológica Rápida - Curitiba: Governo do Estado do Paraná/ STCP Engenharia de Projetos Ltda, 2004.

7. MARGARIDO, T.C.C. Mamíferos do Parque Estadual de Caxambu, Castro, Paraná. Curitiba, 1989. Dissertação (Mestrado em Zoologia). Universidade Federal do Paraná. 216p.

8. MELO, M.S. et al. Patrimônio Natural dos Campos Gerais. Ponta Grossa: UEPG, 2003. Disponível em: www.uepg.br/natural

9. MORO, R.S.; SCHMITT, J.; DIEDRICHS, L. A Estrutura de um fragmento da mata ciliar do Rio Cará-Cará, Ponta Grossa, PR. Publicatio UEPG, v.7, n.1, p. 19-38, 2001.

10. MULLER, M.F.; REIS, N.R. dos. Partição de recursos alimentares entre quatro espécies de morcegos frugívoros (Chiroptera, Phyllostomidae). Rev. Bras. Zool., v.9, n.3/4, p. 345-355, 1992.
11. PIJL, L Van der. Principles of dispersal in higher plants. New York: Springer-Verlag, 1972.

12. REIS, N.R. dos; BARBIERI, I.P.L.; LIMA, I.P.; PERACHI, A.L. O que é melhor para manter a riqueza de espécies de morcegos (Mammalia, Chiroptera): um fragmento florestal grande ou vários fragmentos de pequeno tamanho? Rev. Bras. Zool., v.20, n.2, p. 225-230, 2003.

13. TAKEDA, I.J.M.; MORO, R.S.; KACZMARECH, R.; BAHLS, L.M.C.; BOURGUIGNON, M.V.; SCHARDOSIN, E. Levantamento florístico do Parque Municipal Boca da Ronda, Ponta Grossa, PR. Publicatio UEPG, v.1, n.4, p. 49-63, 1998.

14. THOMAS, O. List of the mammals obtained by Dr. Franco Grillo in the Province of Paraná, Brazil. Annali dei Museo Civico di Storia Naturali di Genova, v.2, n.20, p. 546-549, 1899.

15. YALDEN, D.W.; MORRIS, P.A. The live of bats. London: Red Wood Burn, 1975.

16. ZANON, C.M.V. Morcegos (Mammalia, Chiroptera) da região de Ponta Grossa, Campos Gerais, Paraná, Brasil. Londrina, 2004. Dissertação (Mestrado em Zoologia). Universidade Estadual de Londrina. 